\title{
STRUCTURE AND PHASE COMPOSITION OF W-Si MULTILAYER X-RAY MIRRORS
}

\author{
Yu.P. Pershyn, I.G. Shipkova, O.Yu. Devizenko, V.V. Mamon, V.S. Chumak, \\ V.V. Kondratenko \\ National Technical University "Kharkiv Polytechnic Institute" \\ str. Kyrpychev 2, Kharkiv, 61002, Ukraine \\ E-mail: persh@kpi.kharkov.ua, https://orcid.org/0000-0001-9092-0078 \\ Received July 23, 2018; revised August 28, 2018; accepted September 7, 2018
}

\begin{abstract}
X-ray diffractometry $(\lambda \sim 0.154 \mathrm{~nm})$ was used to study the phase structure, composition and construction of W/Si multilayer X-ray mirrors (MXMs) with tungsten layer thicknesses of $t_{\mathrm{W}}<10 \mathrm{~nm}$ obtained by direct-current magnetron sputtering. Two series of samples were fabricated with different tungsten deposition rates, which differ approximately by a factor of $4: \sim 0.60 \mathrm{~nm} / \mathrm{s}$ and $\sim 0.15 \mathrm{~nm} / \mathrm{s}$. It is shown that tungsten layers have a polycrystalline (BCC) structure at thicknesses $\mathrm{t}_{\mathrm{W}}>2.7 \mathrm{~nm}$, and at $\mathrm{t}_{\mathrm{W}}<1.9 \mathrm{~nm}$ they are amorphous. Using the $\sin ^{2} \Psi$-method, it was found that in thin crystalline layers of tungsten $\left(t_{\mathrm{W}}<10 \mathrm{~nm}\right)$, more than 3 at.\% Si can be contained. Tensile stresses in the layers of crystalline tungsten do not exceed $1.1 \mathrm{GPa}$. The construction of the radial distribution functions of atoms made it possible to establish that amorphous layers of tungsten have an arrangement of atoms close to $\beta$-W. In all samples, formation of silicide interlayers is observed at the interfaces, as a result of which the actual thickness of the tungsten layers is less than the nominal one. Amorphous silicide layers, necessarily formed at the stage of MXM manufacturing, contain tungsten disilicide. Depending on the deposition rate, disilicide can have an arrangement of atoms close to either the tetragonal phase, $\mathrm{t}$-WSi $\mathrm{W}_{2}$ $(\sim 0.6 \mathrm{~nm} / \mathrm{s})$, or to the hexagonal phase, $\mathrm{h}-\mathrm{WSi}_{2}(\sim 0.15 \mathrm{~nm} / \mathrm{s})$. An improved model for the construction of amorphous W/Si MXMs is presented. Mechanisms for the formation of silicide layers are proposed, according to which the bottom silicide interlayers (W-on-Si) are formed mainly by ballistic mixing of tungsten and silicon atoms, and the top ones due to diffusion inermixing. The interdiffusion coefficients were estimated, which made it possible to establish that the effective surface temperature of deposited layers can be at least $250^{\circ}$ above the substrate temperature. The ways of reducing the interface interaction are suggested.
\end{abstract}

KEY WORDS: multilayer X-ray mirror, silicide layers, tungsten disilicide, amorphous layers, formation mechanism

\section{СТРУКТУРА І ФАЗОВИЙ СКЛАД БАГАТОШАРОВИХ РЕНТГЕНІВСЬКИХ ЗЕРКАЛ W-Si \\ Ю.П. Першин, І.Г. Шипкова, О.Ю. Девізенко, В.В. Мамон, В.С. Чумак, В.В. Кондратенко \\ Національний технічний університет «Харківський політехнічний інститут» вул. Кирпичова 2, Харків, 61002, Украӥна}

Методами рентгенівської дифрактометрії ( $\lambda \sim 0,154$ нм) досліджена фазова структура, склад і будова багатошарових рентгенівських дзеркал (БРД) W/Si 3 товщиною шарів вольфраму $\mathrm{t}_{\mathrm{W}}<10$ нм, отриманих методом прямоточного магнетронного розпилення. Досліджено дві серії зразків, виготовлених з різними швидкостями осадження вольфраму, які відрізняються приблизно в 4 рази: $\sim 0,60 \mathrm{i} \sim 0,15$ нм/с. Показано, що при товщині $\mathrm{t}_{\mathrm{W}}>2,7$ нм шари вольфраму мають полікристалічну (ОЦК) структуру, а при $\mathrm{t}_{\mathrm{W}}<1,9$ нм вони аморфні. За допомогою $\sin ^{2} \Psi$-методу встановлено, що в тонких кристалічних шарах вольфраму $\left(\mathrm{t}_{\mathrm{W}}<10\right.$ нм) може міститися більше 3 ат.\% $\mathrm{Si}$. Розтягувальні напруження в шарах кристалічного вольфраму не перевищують 1,1 ГПа. Побудова функцій радіального розподілу атомів дозволила встановити, що аморфні шари вольфраму мають розташування атомів, близьке до $\beta$-W. У всіх зразках за рахунок взаємодії на міжфазних межах спостерігається формування силіцидних прошарків, в результаті чого реальна товщина шарів вольфраму менше номінальної. Аморфні силіцидні прошарки, які обов'язково формуються на стадії виготовлення БРД, містять дисиліцид вольфраму. Залежно від швидкості осадження дисиліцид може мати розташування атомів, близьке або до тетрагональної фази, t-WSi 2 ( 0,6 нм/c.), або до гексагональної фази, $\mathrm{h}-\mathrm{WSi}_{2}(\sim 0,15$ нм/c.). Представлена уточнена модель будови аморфних БРД W/Si. Запропоновано механізми формування силіцидних прошарків, згідно з якими нижні силіцидні прошарки (W-на$\mathrm{Si})$ формуються переважно за рахунок балістичного перемішування атомів вольфраму і кремнію, а верхні - внаслідок дифузійного перемішування. Зроблено оцінку коефіцієнтів взаємної дифузії, які дозволили встановити, що ефективна температура поверхні осаджених шарів може бути, щонайменше, на $250^{\circ}$ вище температури підкладки. Запропоновано шляхи зниження міжфазної взаємодії.

КЛЮЧОВІ СЛОВА: багатошарове рентгенівське дзеркало, силіцидні прошарки, дисиліцид вольфраму, аморфні шари, механізм формування

\section{СТРУКТУРА И ФАЗОВЫЙ СОСТАВ МНОГОСЛОЙНЫХ РЕНТГЕНОВСКИХ ЗЕРКАЛ W-Si \\ Ю.П. Першин, И.Г. Шипкова, А.Ю. Девизенко, В.В. Мамон, В.С. Чумак, В.В. Кондратенко \\ Начиональный технический университет «Харьковский политехнический институт» ул. Кирпичева 2, Харьков, 61002, Украина}

Методами рентгеновской дифрактометрии ( $\lambda \sim 0,154$ нм) исследована фазовая структура, состав и строение многослойных рентгеновских зеркал (MP3) W/Si c толщиной слоев вольфрама $\mathrm{t}_{\mathrm{W}}<10$ нм, полученных методом прямоточного магнетронного распыления. Исследованы две серии образцов, изготовленных с различными скоростями осаждения вольфрама, которые отличаются примерно в 4 раза: $\sim 0,60$ и $\sim 0,15$ нм/с. Показано, что при толщине $\mathrm{t}_{\mathrm{W}}>2,7$ нм слои вольфрама имеют поликристаллическую (ОЦК) структуру, а при $t_{\mathrm{W}}<1,9$ нм они аморфны. При помощи $\sin ^{2} \Psi$-метода установлено, что в тонких кристаллических слоях вольфрама $\left(\mathrm{t}_{\mathrm{W}}<10\right.$ нм) может содержаться более 3 ат.\% Si. Растягивающие напряжения в слоях кристаллического вольфрама не превышают 1,1 ГПа. Построение функций радиального распределения 
атомов позволило установить, что аморфные слои вольфрама имеют расположение атомов, близкое к $\beta$-W. Во всех образцах за счет взаимодействия на межфазных границах наблюдается формирование силицидных прослоек, в результате чего реальная толщина слоев вольфрама меньше номинальной. Аморфные силицидные прослойки, обязательно формирующиеся на стадии изготовления МР3, содержат дисилицид вольфрама. В зависимости от скорости осаждения дисилицид может иметь расположение атомов, близкое либо к тетрагональной фазе, $\mathrm{t}-\mathrm{WSi}_{2}\left(\sim 0,6 \mathrm{Hм} / \mathrm{c}\right.$.), либо к гексагональной фазе, $\mathrm{h}-\mathrm{WSi}_{2}$ ( $\sim, 15$ нм/с.). Представлена уточненная модель строения аморфных MP3 W/Si. Предложены механизмы формирования силицидных прослоек, согласно которым нижние силицидные прослойки (W-на-Si) формируются преимущественно за счет баллистического перемешивания атомов вольфрама и кремния, а верхние - вследствие диффузионного перемешивания. Сделана оценка коэффициентов взаимной диффузии, которые позволили установить, что эффективная температура поверхности осаждаемых слоев может быть, по меньшей мере, на $250^{\circ}$ выше температуры подложки. Предложены пути снижения межфазного взаимодействия.

КЛЮЧЕВЫЕ СЛОВА: многослойное рентгеновское зеркало, силицидные прослойки, дисилицид вольфрама, аморфные слои, механизм формирования

Область мягкого рентгеновского излучения (МРИ) $(1<\lambda<10$ нм) по сравнению с областью видимого и примыкающей к ней ультрафиолетового (УФ) излучения привлекательна своими дополнительными возможностями. Так получение информации о химическом составе твердых тел и поверхностей осуществляется здесь проще, поскольку нет необходимости анализировать десятки линий. Его низкая проникающая способность позволяет получать изображения малоконтрастных биологических объектов, в частности в области «водяного» [1] и «углеродного» [2] окна, с минимальным количеством вносимых артефактов, связанных с приготовлением исследуемого образца. Кроме того, достигнутый уровень развития проекционной рентгеновской литографии показывает, что уже в ближайшем будущем начнется постепенный переход промышленных методов получения интегральных электронных схем с УФ на рентгеновскую литографию с минимальным размером элементов менее 10 нм [3].

Многослойные рентгеновские зеркала (МР3) являются самыми эффективными рентгено-оптическими элементами в области МРИ для закритических углов по сравнению с массивными зеркалами [4,5], дифракционными решетками [6] и линзами Френеля [7]. Они способны отражать, фокусировать и монохроматизировать МРИ при различных углах вплоть до нормального падения. МРЗ на основе пары материалов W-Si наиболее востребованы для анализа содержания легких элементов (от кислорода до кремния) [8,9], а также переходных металлов 4-го периода Периодической системы элементов, имеющих характеристические спектральные L-линии в области длин волн $\lambda \approx 1-2$ нм. Толщины слоев в таких зеркалах составляют 1-3 нм, а число пар слоев превышает 100. Кроме того, они используются в телескопах жесткого рентгеновского излучения с $\lambda<0.1$ нм [10]. Их свойства стабильны во времени и при умеренном разогреве $\left(\mathrm{T}<250-300^{\circ} \mathrm{C}\right)$.

Несмотря на их широкое применение, практические коэффициенты отражения для MP3 W/Si не превышают 50\% от теоретических. Основной причиной этого является взаимодействие слоев на стадии изготовления с образованием силицидов, которые существенно снижают оптический контраст на границах раздела слоев. Для дальнейшего повышения эффективности MP3 W/Si необходимо, по меньшей мере, уменьшить толщину силицидных прослоек. В качестве первого шага в этом направлении необходимо зафиксировать масштабы перемешивания, оценить фазовый и химический состав силицидных прослоек, их толщину. Однако это не является простой задачей, хотя бы потому, что большинство MP3 W/Si aморфны, a масштабы перемешивания составляют $\sim 1$ нм. Последующие шаги могут включать в себя выявление механизмов формирования силицидных прослоек, управление параметрами получаемых прослоек (состав, толщина, плотность), поиск методов, подавляющих силицидообразование и т.д.

Информация об особенностях межфазного взаимодействия слоев вольфрама и кремния, кроме многослойной рентгеновской оптики, востребована при изготовлении СБИС (динамические запоминающие устройства [11], барьерных слоев [12,13], пленочных сопротивлений [14], разводки для микросхем [15,16] и т.д.); однофотонных детекторов $[17,18]$; пассивирующих покрытий, работающих при повышенной температуре [19]; термоэлементов [20]; для термоядерного синтеза [21], и др. Многослойность облегчает изучение вопросов фазообразования, поскольку позволяет многократно усилить проявление какой-либо особенности (например, степени перемешивания слоев W и $\mathrm{Si}$ ) и помогает количественно ее оценить.

Ранее мы уже установили [22], что на границах слоев W-Si образуются аморфные силицидные прослойки; оценили плотности отдельных слоев и построили 4-х слойную модель роста MP3 W/Si.

Цель данной работы - оценить фазовый состав силицидных прослоек и структуру слоев $\mathrm{W}$, a также их химический состав. Здесь также будут рассмотрены возможные механизмы формирования силицидных прослоек и способы уменьшения их толщины.

\section{МЕТОДИКА ЭКСПЕРИМЕНТА}

Многослойные зеркала W/Si изготавливались методом магнетронного распыления на постоянном токе в среде аргона при давлении $\sim 0,3$ Па. В качестве мишеней использовались диски вольфрама (99,5\%) и кремния (99,99\%) диаметром 100 мм, расположенные симметрично относительно оси вращения карусели. Подложка, 
закрепленная на карусели, последовательно экспонировалась над мишенями в фиксированном положении над их центрами. Скорость осаждения компонентов зависела от режимов работы магнетронов. В работе изготавливалось две серии образцов со скоростями осаждения: 1) 0,6 нм/с (прикладываемая мощность на вольфрамовом магнетроне $\mathrm{P}_{\mathrm{W}} \sim 35$ Вт) и $\sim 1,21 \mathrm{HM} / \mathrm{c}$ (мощность на кремниевом магнетроне $\mathrm{P}_{\mathrm{Si}} \sim 150$ Вт); 2) $\sim 0,15 \mathrm{Hм} / \mathrm{c}\left(\mathrm{P}_{\mathrm{W}} \sim 9 \mathrm{BT}\right)$ и $\sim 0,42 \mathrm{Hм} / \mathrm{c}\left(\mathrm{P}_{\mathrm{Si}} \sim 50 \mathrm{BT}\right)$. В качестве подложек использовались сверхгладкое стекло и полированный кремний со среднеквадратичной шероховатостью поверхности 0,3-0,5 нм.

Толщины однослойных покрытий и периоды многослойных зеркал измерялись методом малоугловой рентгеновской рефлектометрии $\left(2 \theta<15^{\circ}\right)$ на дифрактометре ДРОН-3М в излучении $\mathrm{Cu} K \alpha_{1}(\lambda=0,154$ нм $)$ с первичным кристаллом-монохроматором (110)Si и последующим моделированием экспериментальных спектров в программе, рассчитывающей коэффициенты отражения по формулам Френеля.

Для изучения фазового состава MP3 W/Si, мы сделали рентгеновские съемки образцов на больших углах $\left(2 \theta=15-130^{\circ}\right)$ в излучении $\mathrm{CuK \alpha}(\lambda=0,1542$ нм). При этом осуществлялось как $\theta-2 \theta$, так и $2 \theta$-сканирование детектором в скользящей геометрии съемки при фиксированном угле падения $\alpha=2,1^{\circ}$ (для образцов 1 -й серии) и $\alpha=1,4^{\circ}$ (для 2-й серии) с графитовым кристаллом-монохроматором перед детектором.

Для исследования структуры аморфных зеркал применялся метод построения функций радиального распределения атомов (ФРРА). В аморфных материалах этот метод позволяет определять радиусы координационных сфер и координационное число в первой сфере [23]. Рентгеновские съемки проводились на дифрактометре ДРОН-3М в излучении $\mathrm{CuK \alpha}$ в скользящей геометрии $\left(\theta=1,4^{\circ}\right)$ с графитовым кристалломмонохроматором перед детектором. При построении интерференционной функции вводились следующие поправки: дисперсионные поправки к атомным факторам рассеяния, поправки на поляризацию, на поглощение, на комптоновское (некогерентное) рассеяние, а также проводилась нормировка кривой интенсивности. Наличие нескольких компонент в исследуемом образце отражено при вычислении усредненных значений атомных факторов, поправок на поглощение, средней атомной плотности с учетом их атомной концентрации. С помощью Фурье-преобразования интерференционной функции была рассчитана ФРРА. Координационное число в первой координационной сфере определяли как площадь под линией ФРРА вблизи первого пика, ограниченной соседними минимумами. Для устранения ложных пиков ФРРА, вызванных обрывом кривой интенсивности, применялось умножение интерференционной функции на экспоненциальную модифицирующую функцию.

\section{РЕЗУЛЬТАТЫ И ИХ ОБСУЖДЕНИЕ}

Мы изготовили 2 серии многослойных рентгеновских зеркал (MP3) W/Si, включающие в себя более 20 образцов. В 1-й серии скорости осаждения вольфрама составляли $\sim 0,6$ нм/с. (для кремния $\sim 1,21$ нм/с.). 3десь мы следили за процессом перехода слоев W из кристаллического состояния в аморфное, а также за особенностями формирования межфазных границ в тонких слоях вольфрама $\left(\mathrm{t}_{\mathrm{W}}<0,75 \mathrm{Hм}\right)$.

Во 2-й серии скорость осаждения вольфрама были почти в 5 раза ниже $(0,148$ нм/с.), чем в 1-й серии. Здесь мы последовательно изменяли толщину W от $\sim 0,34$ до $\sim 1,7$ нм с шагом $\sim 0,1$ нм, сохраняя постоянным номинальное отношение толщины слоев $\left(\mathrm{t}_{\mathrm{W}} / \mathrm{t}_{\mathrm{Si}} \sim 0.35\right)$ в периоде для всех образцов, и отслеживали изменение фазового состава МРЗ. Во 2-й серии мы имели дело только с аморфными слоистыми системами.

\section{Фазовый состав MP3 W/Si первой серии}

На рис. 1 представлены дифрактограммы для МР3 со слоями вольфрама в диапазоне от $~ 9,8$ до $\sim 0,5$ нм. Для относительно толстых слоев вольфрама $\left(2,7<\mathrm{t}_{\mathrm{W}}<9,8\right.$ нм) характерна поликристаллическая ОЦК структура (c-W) с размером зерен, оцененным по методу Шеррера, немного меньше номинальной толщины вольфрама ( 2,3 и 9,4 нм для крайних значений толщины слоев). Это связано с тем, что часть вольфрама ( $\mathrm{t}_{\mathrm{W}} \sim 0,4$ нм) взаимодействует с кремнием на этапе изготовления МР3, формируя силицидные прослойки. Угловое положение пика $(110) \mathrm{W}$ находится на углах $2 \theta \sim 40,6^{\circ}$, что немного больше табличного значения 40,264 ${ }^{24}$ ]; это может указывать на то, что слои вольфрама напряжены, либо в них присутствуют (растворены) примесные атомы.

Уменьшение толщины вольфрама до 1,3 нм приводит к аморфизации слоя вольфрама. При этом сохраняется всего три пика, самый интенсивный из которых только немного смещается от исходного положения (110)W в сторону меньших углов $\left(2 \theta: 40,6^{\circ} \rightarrow 40,5^{\circ}\right)$, однако уширяется в несколько раз $\left(2,4^{\circ} \rightarrow 8,4^{\circ}\right)$ (рис. 1с, рис. 2). Остальные два пика уже не расположены в позициях дифракционных пиков поликристаллического вольфрама и находятся в положениях, для которых $\theta_{2} / \theta_{1} \sim 1,7$ и $\theta_{3} / \theta_{1} \sim 2,1$ (что соответствует аморфному состоянию для модели твердых сфер).

Дальнейшее уменьшение толщин вольфрама до $\sim 0,75$ нм и менее помимо уширения приводит к значительному смещению самого сильного пика, по меньшей мере, на $2,8^{\circ}\left(2 \theta: 40,5^{\circ} \rightarrow 43,3^{\circ}\right)$. Самые интенсивные пики для кристаллического силицида, согласно справочным данным, находятся на углах $2 \theta \sim 44,6^{\circ}$ (для тетрагональной структуры) и $2 \theta \sim 42,6^{\circ}$ (для гексагональной структуры). Очевидно, что аморфное вещество имеет меньшую плотность, т.е. межатомное расстояние должно быть увеличено по сравнению кристаллическим. Другими словами, пик от аморфного вещества должен наблюдаться на меньших углах по 
отношению к кристаллическому. Поэтому вероятнее всего вольфрам толщиной $\mathrm{t}_{\mathrm{W}} \leq 0,75$ нм находится в связанном состоянии в виде дисилицида и имеет расположение атомов, близкое к тетрагональному.

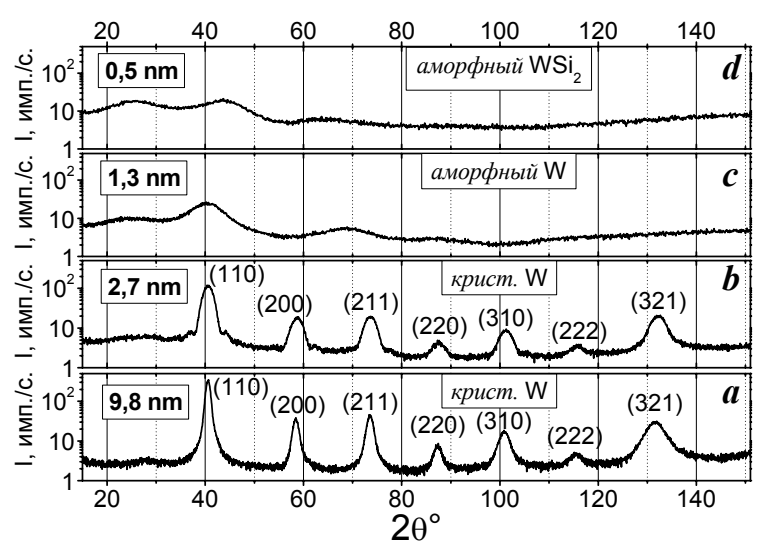

Рис. 1. Рентгеновские дифрактограммы многослойных образцов $\mathrm{W} / \mathrm{Si}(\lambda=0,154$ нм $)$ номинальные толщины слоев вольфрама 9,8 (a); 2,7 (b); 1,3 (c); и 0,5 (d) нм.

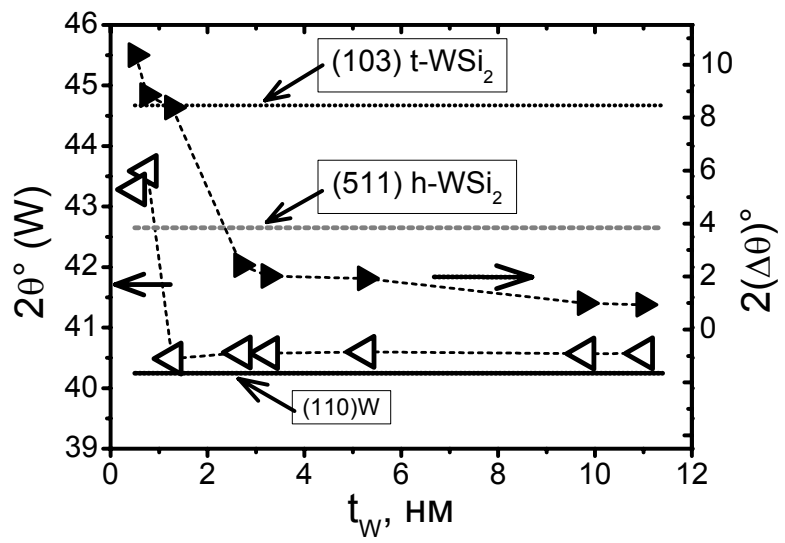

Рис. 2. Зависимость углового положения наиболее интенсивного пика (светлые треугольники) и его ширины (темные треугольники) на фазовых дифрактограммах для MP3 W/Si, приведенных на рис.1, от толщины слоев вольфрама.

Мы использовали $\sin ^{2} \Psi$-метод для оценки напряжений в слоях вольфрама, которые находятся в кристаллическом состоянии ( $\left.\mathrm{t}_{\mathrm{W}} \geq 2,7 \mathrm{HM}\right)$. Поскольку фазовые дифрактограммы записывались в скользящей геометрии, в последующих расчетах мы использовали все дифракционные пики. Для начала мы построили зависимость измеренного параметра решетки от $\sin ^{2} \Psi$, и затем определили параметр решетки, $a_{0}$, вольфрама в ненапряженном состоянии $\left\{\right.$ при $\sin ^{2} \Psi=2 v /(1+v) \approx 0,45 ; v=0,29$, коэффициент Пуассона $\}$. На зависимости $a_{0}=f\left(\mathrm{t}_{\mathrm{w}}\right)$, приведенной на рис. 3, видно, что период решетки меньше (на 0,2-0,4\%) табличной величины (пунктирная линия в верхней части рисунка), и разница по мере увеличения толщины слоев вольфрама уменьшается. Более низкие значения $a_{0}$ могут быть связаны с наличием таких примесей, как $\mathrm{C}, \mathrm{N}, \mathrm{O}, \mathrm{Si}$, поскольку ковалентные радиусы этих атомов, меньше, чем $\mathrm{y}$ W. Однако наблюдаемый переход из аморфного состояния в кристаллическое, которое наблюдается между 1,7 нм и 2,7 нм в каждом слое вольфрама многослойного зеркала, указывает на преимущественное влияние кремния, ослабевающее с ростом толщины слоя вольфрама. Если бы преобладающим было влияния углерода, кислорода либо азота, тогда мы не должны были наблюдать переход слоев вольфрама в кристаллическое состояние, поскольку условия их осаждения не менялось, и указанные примесные атомы оказывали бы аморфизирующее влияние и при $\mathrm{t}_{\mathrm{W}} \sim 10$ нм. Подобный переход из аморфного состояние в кристаллическое для слоев молибдена под воздействием кремния наблюдали в многослойной системе Mo/Si при $2<\mathrm{t}_{\mathrm{Mo}}<2,6$ нм [25-27], где указывалось, что слои Мо кристаллизуются, когда концентрации кремния в слоях Мо становится ниже предела равновесной растворимости.

Полагая, что уменьшение периода решетки в слоях вольфрама вызвано только примесными атомами кремния, мы на основании правила Вегарда оценили количество растворенного кремния. Для этого мы использовали данные исследований для молибдена [28], полагая, что свойства молибдена и вольфрама, как представителей одной подгруппы периодической системы элементов, близки. Полученные данные представлены на вставке к рис. 3. Здесь можно видеть, что для тонких кристаллических слоев вольфрама $\left(\mathrm{t}_{\mathrm{W}} \sim 2,7\right.$ нм) количество растворенного кремния превышает 6 ат.\%. Согласно равновесной фазовой диаграмме 
W-Si [29] максимальное количество кремния, которое может раствориться в вольфраме при 2360K, составляет $\sim 5,5$ ат.\%. С одной стороны, это может указывать на присутствие в слоях вольфрама других примесей. С другой стороны, более низкие плотности, характерные для материалов в тонкопленочном состоянии [30], в том числе и для вольфрама [22], свидетельствуют о наличии в слоях свободного объема и возможном отклонении предельных значений растворимости от равновесной.

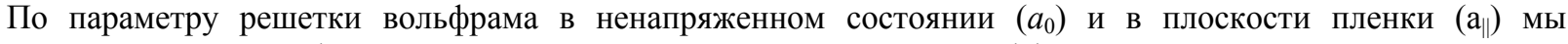
определили величину деформации и ее знак, а затем, используя коэффициент Пуассона и модуль Юнга $(\mathrm{E}=350$ ГПа),- напряжения в слоях вольфрама. Напряжения имеют растягивающий характер (со знаком «+») и находятся в пределах 0,6-1,1 ГПа; относительная погрешность определения напряжений составила $\pm 11 \%$. Эта величина и знак согласуются с уровнем напряжений в MP3 Mo/Si [31].

Таким образом, для первой серии характерно два состояния слоев вольфрама в MP3 W/Si: кристаллическое $\left(\mathrm{t}_{\mathrm{W}} \geq 2,7\right.$ нм) и аморфное $\left(\mathrm{t}_{\mathrm{W}} \leq 1,3\right.$ нм). Кристаллические слои могут содержать до $\sim 6$ ат.\% кремния, и в них присутствуют растягивающие напряжения в плоскости пленки. Аморфные слои вольфрама толщиной $\mathrm{t}_{\mathrm{W}} \leq 0,75$ нм находятся в связанном с кремнием состоянии с расположением атомов, близким к тетрагональному дисилициду $\mathrm{WSi}_{2}$.

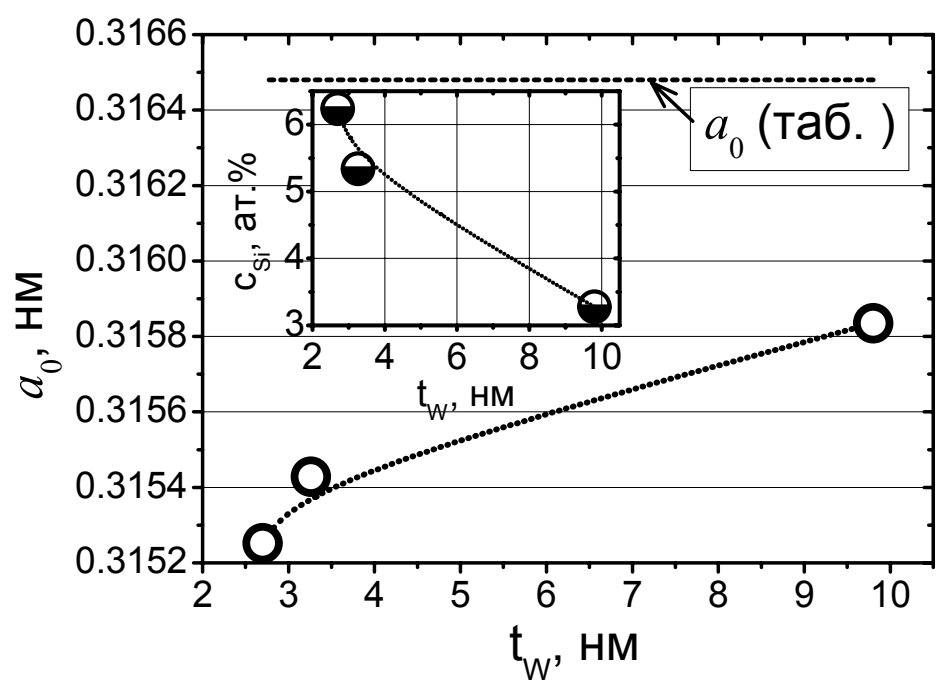

Рис. 3. Параметр решетки $a_{0}$ в слоях вольфрама в ненапряженном состоянии в зависимости от толщины слоев кристаллического вольфрама, $\mathrm{t}_{\mathrm{W}}$. На вставке показана рассчитанная концентрация атомов кремния в решетке вольфрама.

\section{Фазовый состав MP3 W/Si второй серии}

Толщины слоев вольфрама во 2-й серии находились в пределах от 0,4 до 1,9 нм. Примеры двух дифрактограмм с предельными толщинами вольфрама (периоды MP3 d 1 и d 6,2 нм, соответственно) представлены на рис. 4. На них наблюдается всего 3 пика: 1) в районе 26-29, т.е. вблизи интенсивной линии (111)Si; 2) в районе 40-42 , вблизи самой интенсивной линии (110)W; это самый интенсивный пик на всех дифрактограммах; и 3) в районе 66-69, где можно ожидать рефлексы как от кремния, так и от вольфрама и его силицидов. Такое резкое уменьшение количества дифракционных пиков по сравнению с дифрактограммами для кристаллических слоев на рис. 1a,b, уменьшение их интенсивности (в 2-7 раз), а также их значительное уширение $\left(2 \Delta \theta>5^{\circ}\right)$ как для образцов на рис. $1 \mathrm{c}, \mathrm{d}$, указывают на то, что все слои находятся в аморфном состоянии. Здесь также видно, что вторые пики вблизи $40-42^{\circ}$ для обоих образцов не совпадают и смещены друг относительно друга, по меньшей мере, на $1,7^{\circ}$.

Интенсивность 1-го пика $\left(26^{\circ}-2^{\circ}\right)$ существенно подрастает для малопериодного образца по отношению к соответствующему 2-му пику. Поскольку амплитуда рассеивания рентгеновского излучения атомами вольфрама примерно в 5 раза выше, чем рассеивание атомами кремния, то даже с учетом реального соотношения толщин слоев в МР3, у нас должно получаться, по меньшей мере, девятикратное превышение интенсивности линии вольфрама $\left(2 \theta \sim 41^{\circ}\right)$ над кремнием $\left(2 \theta \sim 28^{\circ}\right)$. Однако для малопериодного образца фактически наблюдается различие только на 20\%. Кроме того, подрастает также интенсивность 3-го пика для MP3 с периодом d 1 нм. Все это указывает на то, что фазовый состав МРЗ меняется с изменением периода; и, по меньшей мере, 1-й и 3-й пики не относятся к аморфному кремнию. Рассеивающая способность рентгеновского излучения молекулой $\mathrm{WSi}_{2}$ примерно в 3,4 раза выше, чем у атомов кремния, не говоря уже о других силицидах; и поскольку образцы аморфны, такая небольшая разница в интенсивностях двух соседних пиков для образца с периодом $\sim 1$ нм, указывает на то, что 1-й пик может принадлежать не к аморфному кремнию, а к одному из силицидов, например $\mathrm{WSi}_{2}$, который имеет три интенсивных линии в этой области углов $\left(22,8^{\circ} ; 26,8^{\circ}\right.$ и $\left.28,0^{\circ}\right)$ [32]. 


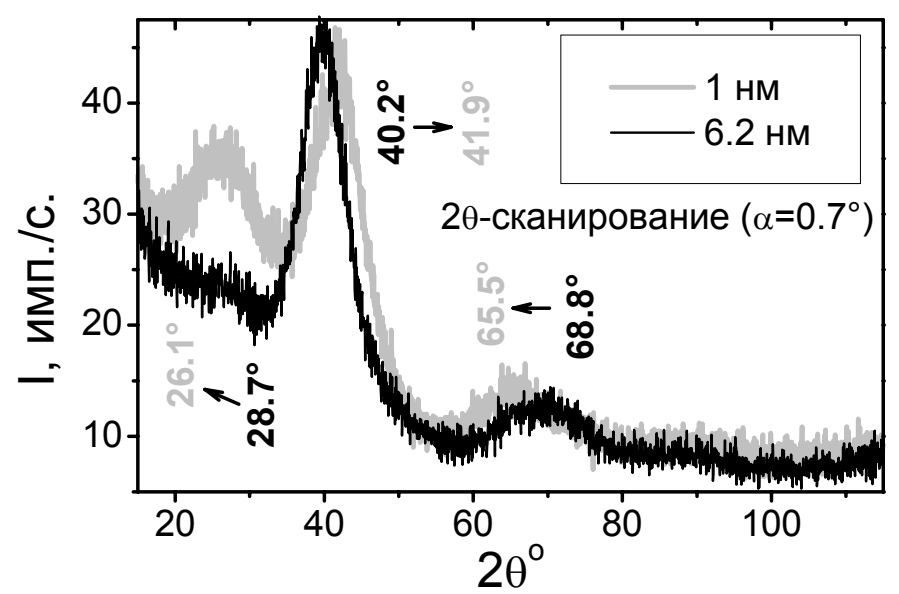

Рис. 4. Фазовые дифрактограммы для MP3 W/Si с толщиной вольфрамового слоя $\mathrm{t}_{\mathrm{W}} \sim 0,4$ нм (серая линия) и $\mathrm{t}_{\mathrm{W}} \sim 1,9$ нм (черная линия), полученные в скользящей геометрии (угол падения $\alpha=1,4^{\circ}$ ). Цифрами указаны угловые положения пиков, демонстрирующие их смещение друг относительно друга.

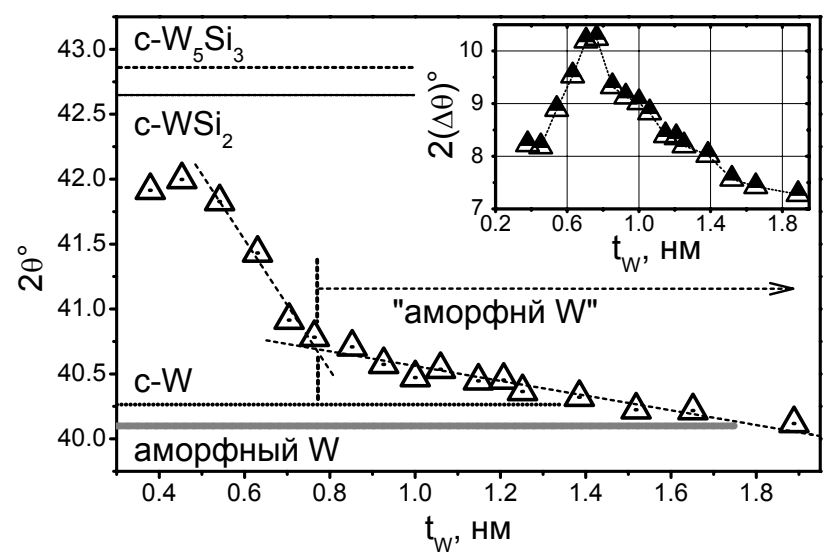

Рис. 5. Зависимость углового положения наиболее интенсивных пиков $\left(2 \theta \sim 41^{\circ}\right)$ от номинальной толщины слоев вольфрама. Горизонтальными линиями показаны аналогичные табличные значения для различных кристаллических веществ. На вставке приведена зависимость ширины пиков $\left(2 \theta \sim 41^{\circ}\right)$ на середине высоты от толщины слоев вольфрама.

Угловые положения наиболее интенсивных дифракционных пиков для остальных многослойных образцов $\left(0,4<\mathrm{t}_{\mathrm{W}}<1,9\right.$ нм) лежат в промежутке между пиками, приведенными на рис. 4, и показаны на рис. 5 в виде треугольников. На этот же рисунок горизонтальными пунктирными линиями добавлены угловые положения наиболее интенсивных линий для различных кристаллических фаз, образование которых возможно в многослойной системе W/Si, а именно: (110)W (ОЦК), (411) $\mathrm{W}_{5} \mathrm{Si}_{3}$ (тетраг.) и (511)WSi 2 (гексаг.). Наблюдаемую на рис. 5 зависимость можно условно разбить на 3 участка: 1) $\mathrm{t}_{\mathrm{W}}<0,54 \mathrm{Hм}$, где угловое положение 2 -го пика меняется мало; 2) 0,54<t $\mathrm{t}_{\mathrm{W}}<0,76$ нм - область динамичного изменения положения 2-го пика; 3) $\mathrm{t}_{\mathrm{W}}>0,76$ нм область монотонного уменьшения углов.

Обращает на себя внимание, что смещение вторых пиков для образцов с тонким вольфрамом существенно разнятся в 1-й и 2-й сериях образцов: в 1-й серии они наиболее близки к $100 \%$-линии тетрагонального $\mathrm{WSi}_{2}$ (рис. 2), а во 2-й - к гексагональной фазе $\mathrm{WSi}_{2}$. Мы полагаем, что в обоих случаях сначала образуется гексагональный силицид (фаза, существующая при высоких температурах), поскольку энергии распыляемых атомов, если не учитывать отвод тепла, достаточно большие, чтобы расплавить поверхность подложки. Другими словами, при распылении возможна «закалка» высокотемпературной фазы. При более высокой скорости осаждения дополнительная энергия может приводить к «отжигу» осаждаемого слоя и, соответственно, к смене фазы.

Зависимости на 2-м и 3-м участках (рис. 5) мы аппроксимировали прямыми, которые пересекаются при $\mathrm{t}_{\mathrm{W}} \sim 0,77$ нм. Мы полагаем, что при этой толщине в MP3 W/Si может проявляться «чистый» вольфрам, поскольку угловое положение этого пика смещается в сторону вольфрама с ростом толщины вольфрамового слоя. Поэтому в диапазоне толщин вольфрама 0,54-0,76 нм (2-й участок на рис. 5) в МРЗ маловероятно появление другого силицида (например, $\mathrm{W}_{5} \mathrm{Si}_{3}$ ). На 3-м участке наблюдаются экспериментальные точки, которые находятся ниже углового положения $100 \%$-линии $(110) \mathrm{W}$ для кристаллического вольфрама, т.е. аморфный вольфрам имеет плотность ниже табличной. Фактически «чистый» вольфрам в процессе осаждения должен 
появляться уже при $\mathrm{t}_{\mathrm{W}}>0,54$ нм (т.е. начало сдвига пика на рис. 5), однако частично он взаимодействует с осаждаемым на него кремнием и принимает участие в формировании верхней (Si-на-W) силицидной прослойки. При $\mathrm{t}_{\mathrm{W}}>0,77$ нм влияние появившегося аморфного вольфрама на формирование дифракционной картины становится преобладающим.

Силицидный слой должен присутствовать во всех образцах, поскольку невозможно избежать начальной стадии перемешивания вольфрама и аморфного кремния при осаждении тонких слоев W. Поэтому начиная со 2-го участка $\left(\mathrm{t}_{\mathrm{W}}>0,54\right.$ нм), наблюдаемые на рис. 5 пики являются суммой, по меньшей мере, двух пиков: силицидного и вольфрамового. Это видно на зависимости ширины $(2 \Delta \theta)$ 2-го пика от толщины $t_{\mathrm{W}}$, которая имеет явный максимум (вставка на рис. 5): до $\mathrm{t}_{\mathrm{W}} \sim 0,7$ нм она растет от $\sim 8,3^{\circ}$ до $\sim 10,3^{\circ}$, а затем после $\mathrm{t}_{\mathrm{W}} \sim 0,76$ нм падает до $\sim 7,3^{\circ}$. Рост ширины 2-го пика означает, что с увеличением толщины слоя вольфрама меняется состав $\mathrm{W}$-содержащего слоя, т.е. наряду с силицидным пиком появляется и начинает расти пик от аморфного вольфрама. Уменьшение ширины пика после 0,76 нм означает, что влияние пика от аморфных слоев W становится преобладающим за счет превышения его удельного объема над объемом $\mathrm{WSi}_{2}$, a также (с его меньшей физическая шириной) монофазностью этого слоя.

Поскольку мы пришли к выводу о многофазности вольфрам-содержащих слоев после анализа дифрактограмм от 17 многослойных образцов, мы решили убедиться в многофазности «толстых» слоев вольфрама, анализируя дифрактограмму только от одного образца. Для этого мы выбрали образец с самой большой толщиной вольфрама $\left(\mathrm{t}_{\mathrm{W}} \sim 1,9\right.$ нм). Чтобы «прощупать» состав слоев вольфрама мы при помощи стоячей волны создали условия, при которых интенсивность рентгеновских лучей перераспределяется в пределах каждого слоя вольфрама. Для этого мы последовательно меняли угол падения в пределах 1-го малоуглового пика $\left(\theta \sim 0,8^{\circ}\right)$ от $0,5^{\circ}$ до $1,2^{\circ}$ и осуществляли $2 \theta$-сканирование в диапазоне углов $20-60^{\circ}(2 \theta)$, чтобы проследить динамику изменения углового положения 2-го пика $\left(2 \theta \sim 41^{\circ}\right)$. Результаты съемок показаны на рис. 6. Мы видим, что угловое положение наиболее интенсивного пика (вертикальные палочки) на фазовой дифрактограмме меняется: сначала постепенно уменьшается при подходе к малоугловому пику (серая линия) от $40,1^{\circ}$ до почти $39,8^{\circ}$, а затем при переходе через малоугловой пик растет более чем на $0,7^{\circ}\left(39,8^{\circ} \rightarrow 40,6^{\circ}\right)$, и $^{\circ}$ снова падает до $\sim 40,2^{\circ}$ за пределами малоуглового пика. Если учесть, что при такой геометрии съемки интенсивность внутри слоев вольфрама только перераспределяется (а не исключается), и при этом все подслои вольфрам-содержащего слоя участвуют в формировании дифракционной картины, то такие изменения углового положения 2-го пика выглядят довольно большими. Мы также провели статистическую обработку дифрактограмм для 4-х MP3 с одинаковыми параметрами и режимами нанесения (толщина слоев вольфрама, число периодов, величина периода; токи на магнетронах, геометрия нанесения и т.д.), которые были сделаны в разных экспериментах, и получили разброс углового положения 2-го пика менее $\pm 0,05^{\circ}$. Мы полагаем, что эти результаты являются прямым доказательством существования в толстых слоях вольфрама ( $\mathrm{t}_{\mathrm{W}}>0,8$ нм), по меньшей мере, двух фаз: дисилицида вольфрама и «чистого» аморфного вольфрама.

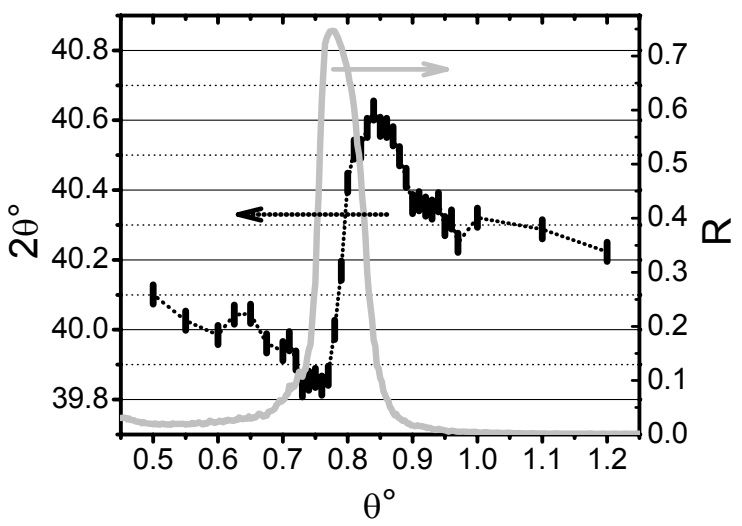

Рис. 6. Изменение углового положения 2-го пика на фазовой дифрактограмме (рис. 5) для MP3 W/Si c t $\mathrm{w}_{\mathrm{W}} 1,9$ нм при изменении угла падения вблизи 1 -го малоуглового пика $\left(\theta \sim 0,8^{\circ}\right)$ от MP3 (см. текст).

\section{Функция радиального распределения атомов (ФРРА) вольфрама}

Для того, чтобы качественно описать структуру аморфных слоев вольфрама, мы рассчитали функции радиального распределения атомов для аморфных образцов 2-й серии на основе дифрактограмм в жесткой рентгеновской области. Из зависимости ФРРА мы брали радиус первой координационной сферы $\left(\mathrm{r}_{1}\right)$ и координационное число $(\mathrm{N})$. Поскольку у вольфрама и его силицидов межатомные расстояния близки, мы не обнаружили какой-либо закономерности на зависимости $\mathrm{r}_{1}=f\left(\mathrm{t}_{\mathrm{W}}\right)$. Однако, как видно на рис. 6, при изменении толщины вольфрама от $\sim 0,4$ до $\sim 1,9$ нм координационные числа монотонно меняются почти в два раза: от $\sim 5$ до $\sim 9$. 


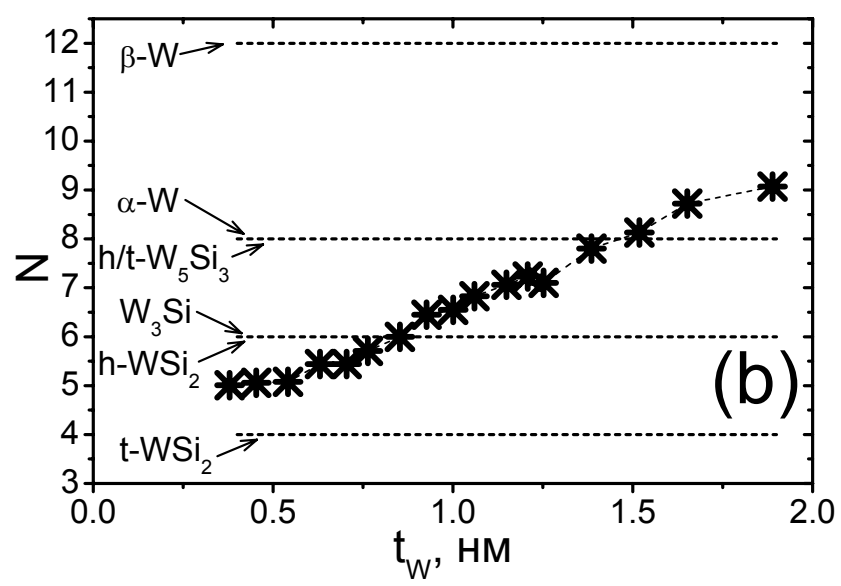

Рис. 7. Зависимость координационного числа N, от номинальной толщины слоев вольфрама в MP3 W/Si.

На основе литературных данных о кристаллической структуре различных соединений W и $\mathrm{Si}$, a также различных модификаций вольфрама мы собрали данные о координационных числах этих веществ (таблица 1) и сравнили их с экспериментальными данными на рис. 6. Табличные координационные числа имеют величины 4 , 6,8 и 12. Для первых трех образцов $\mathrm{N} \sim 5$, что должно соответствовать силициду $\mathrm{WSi}_{2}$. Поскольку в аморфном веществе атомы упакованы менее плотно, по сравнению с кристаллическим, т.е. должны иметь меньшее $\mathrm{N}$, то из данных на рис. 6 можно сделать вывод, что тонкие слои вольфрама в процессе осаждения взаимодействуют с кремнием и образуют гексагональный дисилицид вольфрама.

Координационные числа $(\mathrm{N})$ и структурный тип веществ

Таблица 1.

\begin{tabular}{|c|c|c|c|c|}
\hline № & Вещество & $\mathrm{N}$ & $\begin{array}{c}\text { Структурный } \\
\text { тип }\end{array}$ & Ист. \\
\hline 1 & $\alpha-\mathrm{W}$ & 8 & $\mathrm{~A} 2$ & {$[33]$} \\
\hline 2 & $\beta-\mathrm{W}$ & 12 & $\mathrm{~A} 15$ & {$[34]$} \\
\hline 3 & $\mathrm{~W}_{3} \mathrm{Si}$ & 6 & $\mathrm{~A} 15$ & {$[34]$} \\
\hline 4 & $\mathrm{~h}-\mathrm{W}_{5} \mathrm{Si}_{3}$ & 8 & $\mathrm{D} 8_{8}$ & {$[35]$} \\
\hline 5 & $\mathrm{t}-\mathrm{W}_{5} \mathrm{Si}_{3}$ & 8 & $\mathrm{D} 8_{\mathrm{m}}$ & {$[36]$} \\
\hline 6 & $\mathrm{~h}-\mathrm{WSi}_{2}$ & 6 & $\mathrm{C} 40$ & {$[35]$} \\
\hline 7 & $\mathrm{t}-\mathrm{WSi}_{2}$ & 4 & $\mathrm{C} 11_{\mathrm{b}}$ & {$[36]$} \\
\hline
\end{tabular}

Образцы с номинальными толщинами вольфрама $t_{\mathrm{W}}>1,6$ нм имеют $\mathrm{N} \sim 9$, что выше значений $\mathrm{N}$ для $\alpha-\mathrm{W}$, но ниже, чем для $\beta$-W. Можно предположить, что такие относительно толстые слои вольфрама могут иметь частично структуру $\alpha-\mathrm{W}$ и частично $\beta-\mathrm{W}$. Однако, поскольку во всех образцах, как было показано выше, присутствуют силицидные прослойки, которые начинают образовываться с самого начала осаждения вольфрама и которые могут понижать значение $\mathrm{N}$, то следует ожидать, что реальная величина $\mathrm{N}$ у толстых слоев выше и они могут иметь преимущественно структуру $\beta-\mathrm{W}$.

Для того чтобы убедиться в этом, мы проделали следующие манипуляции. Ранее [22] было показано, что слои $\mathrm{W}$ толщиной $\mathrm{t}_{\mathrm{W}}>1,3$ нм состоят из трех подслоев: 1) при $\mathrm{t}_{\mathrm{W}}<0,7$ нм растет $\left.\mathrm{WSi}_{2} ; 2\right)$ при $0,7<\mathrm{t}_{\mathrm{W}}<1,3$ нм растет силицидная смесь со средним составом $\left.\mathrm{WSi}_{0.6} ; 3\right)$ при $\mathrm{t}_{\mathrm{W}}>1,3$ нм растет собственно вольфрам. Чтобы получить $\mathrm{N}$ только для вольфрамовых слоев, мы сначала привели рентгеновские дифрактограммы к одному периоду, поделив их интенсивность на число периодов. Затем мы последовательно вычитали дифрактограммы для тонких слоев вольфрама от дифрактограмм для более толстых слоев, которые находятся на границах указанных областей. Так из дифрактограммы для самого толстого вольфрама $\left(\mathrm{t}_{\mathrm{W}} \sim 1,9\right.$ нм$)$ мы вычли дифрактограмму $\mathrm{c}_{\mathrm{W}} \sim 1,3$ нм, чтобы убрать силицидную часть и оставить информацию о структуре только слоев вольфрама. Точно также, чтобы оценить структуру второй силицидной прослойки (номинальным составом $\mathrm{WSi}_{0,6}$ ), мы из дифрактограммы с $\mathrm{t}_{\mathrm{W}} \sim 1,3$ нм вычли дифрактограмму $\mathrm{c} \mathrm{t}_{\mathrm{W}} \sim 0,7$ нм. Дифрактограмма для аморфных прослоек «чистого» вольфрама толщиной $t_{\mathrm{W}}>1,3$ нм приведена на рис. 8. По форме она схожа с другими дифрактограммами от аморфных MP3 W/Si, подобно дифрактограммам на рис. 1с,d. Единственное отличие состоит в том, что здесь немного уменьшилось угловое положение самого интенсивного пика по отношению к многослойному образцу с $\mathrm{t}_{\mathrm{W}} \sim 1,9$ нм $\left(40,26^{\circ} \rightarrow 40,1^{\circ}\right)$, и его ширина сузилась на $\sim 40 \%\left(7,3^{\circ} \rightarrow 4,4^{\circ}\right)$ за счет удаления из дифрактограммы силицидной части. Угловое положение для пика от «чистого» аморфного вольфрама мы также нанесли на рис. 5 в виде серой горизонтальной линии. 
По спектру, приведенному на рис. 8, мы рассчитали функцию радиального распределения атомов для аморфных прослоек вольфрама и определили радиус первой координационной сферы и число атомов в них. Увеличенный первый пик ФРРА приведен на рис. 9 вместе с данными для двух модификаций кристаллического вольфрама. Радиус 1-й координационной сферы для аморфных прослоек вольфрама составил $\sim 291$ нм, а координационное число $\sim 12,2$. Сравнение с известными структурными модификациями вольфрама отдает предпочтение $\beta-\mathrm{W}$ в особенности по параметру $\mathrm{N}$.

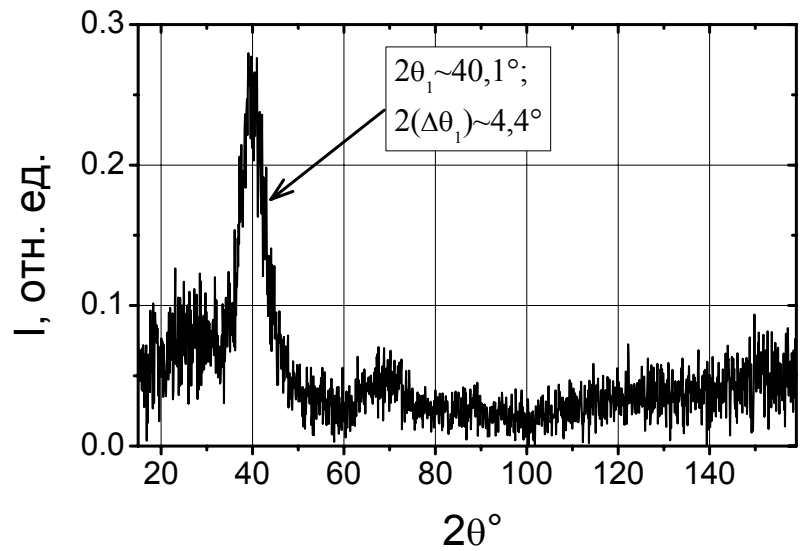

Рис. 8. Рентгеновский спектр для аморфных прослоек вольфрама с $\mathrm{t}_{\mathrm{W}}>1,3$ нм в MP3 W/Si (см. текст).

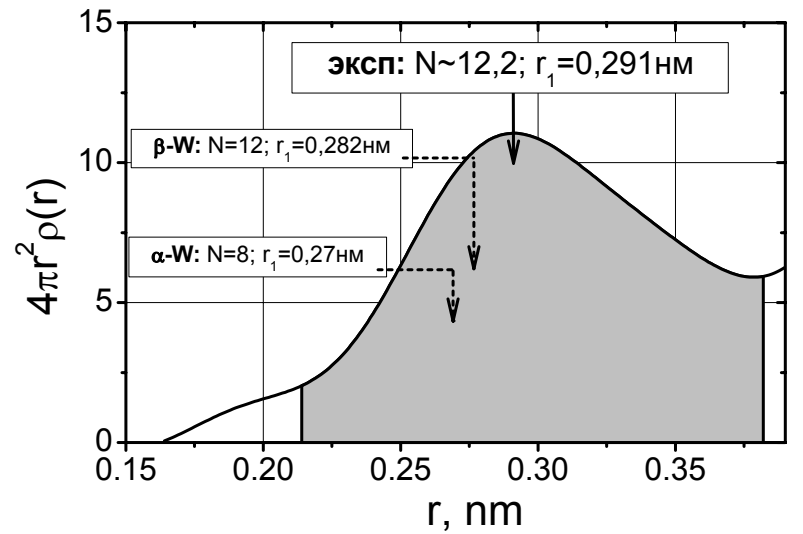

Рис. 9. Изображение 1-го пика функции радиального распределения атомов для аморфных прослоек вольфрама.

Для второй силицидной прослойки мы получили $\mathrm{r}_{1} \sim 0,287$ нм и $\mathrm{N} \sim 10,4$. Если в качестве основного параметра сравнения брать $\mathrm{N}$, то с одной стороны он лежит между $\beta-\mathrm{W}$ и $\alpha-\mathrm{W}$, а с другой - между $\beta$-W и $\mathrm{t}-\mathrm{W}_{5} \mathrm{Si}_{3}$. Если опираться также на параметр $\mathrm{r}_{1}$, то в качестве второго вещества может выступить и $\mathrm{h}-\mathrm{WSi}{ }_{2}$. Последний вариант нам кажется более правдоподобным также и потому, что угловое положение наиболее интенсивного пика на рис. 5 для $\mathrm{t}_{\mathrm{W}}>0,54$ нм только уменьшается с ростом толщины вольфрама, а должен расти, если учесть, что наиболее интенсивная линия от кристаллического силицида $\mathrm{W}_{5} \mathrm{Si}_{3}$ находится при больших углах $\left(42,9^{\circ}\right)$ по отношению к $\mathrm{WSi}_{2}\left(42,6^{\circ}\right)$. Поэтому второй силицидный слой может состоять из смеси $\beta$-W и h$\mathrm{WSi}_{2}$, при этом имея состав, близкий к $\mathrm{WSi}_{0,6}[22]$.

Энтальпии образования для силицидов вольфрама имеют значения $82 \pm 6$ кДж/моль (WSi ${ }_{2}$ и $133 \pm 25$ кДж/моль $\left(\mathrm{W}_{5} \mathrm{Si}_{3}\right)$ [37]. Метод Преториуса [38], который на основе энтальпий образования позволяет предсказать фазу, образующуюся в системе W-Si, отдает предпочтение дисилициду вольфрама во всем диапазоне концентраций кремния. Таким образом, можно прийти к заключению, что на обеих межфазных границах многослойной системы W-Si должен присутствовать $\mathrm{WSi}_{2}$.

По результатам исследований, проведенных в данном подразделе, можно построить уточненную модель роста MP3 W/Si с толщинами $\mathrm{t}_{\mathrm{W}}>1,3$ нм. Мы воспользовались результатами предыдущей работы в отношении толщин силицидных прослоек [22], согласно которым толщина нижней (граница W-на-Si) силицидной прослойки составляет $\sim 1,8$ нм. Хотя она находится в аморфном состоянии, ее структура в ближнем порядке схожа с h-WSi 2 . Верхняя силицидная прослойка (граница $\mathrm{Si}-\mathrm{Ha}-\mathrm{W}$ ) толщиной $\sim 0,9$ нм состоит из дисилицида $\mathrm{h}-$ $\mathrm{WSi}_{2}$ только на $40 \%$ [22]; остальное - $\beta$-W. Собственно аморфный вольфрам, которому, как было показано выше, не дает кристаллизоваться кремний, имеет структуру, близкую к $\beta$-W. Схематическое изображение этой модели представлено на рис. 10. 


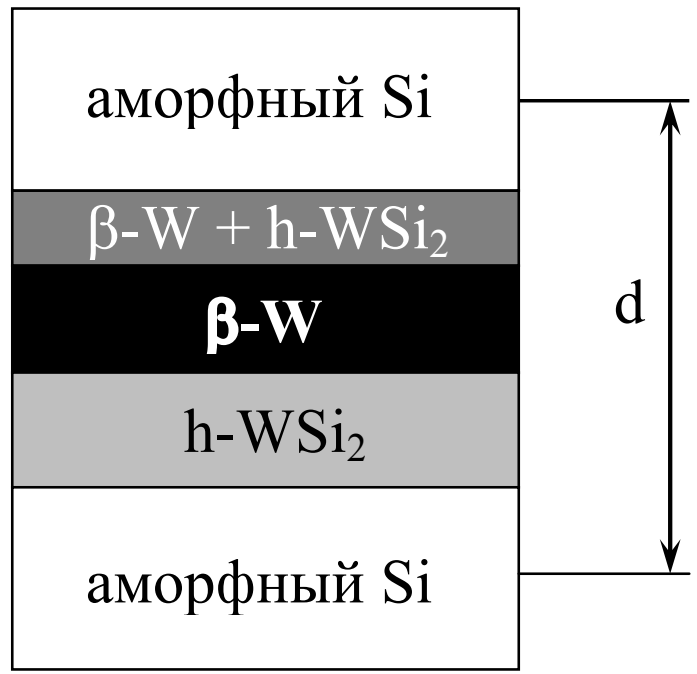

Рис. 10. Уточненная модель роста MP3 W/Si с толщинами слоев вольфрама $\mathrm{t}_{\mathrm{W}}>1,3$ нм.

\section{Механизм роста силицидных прослоек}

Поскольку мы уже установили, что на границах слоев формируются силицидные прослойки, их состав и толщину, то на основе этих данных можно оценить наиболее вероятный механизм их формирования. Для МР3, полученных методом распыления, можно ожидать следующие механизмы формирования силицидов: 1) баллистический, за счет механического внедрения осаждаемых атомов в уже осажденный слой на подложке; 2) диффузионный, за счет разогрева поверхности подложки осаждаемыми атомами и последующей их диффузии и 3) комбинированный, состоящий из первых двух. Для начала на основе рабочих напряжений на магнетронах при помощи программы TRIM [39] мы посчитали энергии распыленных атомов. Рассчитанные данные приведены в таблице 2 .

Для потенциала $\mathrm{U}_{\mathrm{W}}$ 550 B на мишени вольфрама энергия распыленных атомов вольфрама в среднем составляет 232,5 эВ; при этом около 26\% атомов аргона с энергией 126 эВ отражаются от мишени, из которых менее $15 \%$ попадают на подложку. Глубина проникновения атомов вольфрама в слой кремния при нормальном падении составляет $\sim 1,7$ нм. Эта величина соответствует толщине дисилицидного слоя $\left(\mathrm{t}_{\mathrm{WSi} 2} \sim 1,8\right.$ нм) на нижней силицидной границе (W-на-Si). Однако в нашей геометрии распыленные атомы осаждаются на подложку при углах, близких к $45^{\circ}\left( \pm 15^{\circ}\right)$, что снижает глубину проникновения до $\sim 1,2$ нм. Если учесть, что в процессе осаждения образуется дисилицид, то толщина проникновения может понизиться до $\sim 0,7$ нм. Другими словами, величина 1,2 нм - это максимальная глубина проникновения распыленных атомов вольфрама в слой кремния, которую можно ожидать только для начальной стадии осаждения вольфрама. Таким образом, формирование самое большее $2 / 3$ силицидного слоя на нижней границе можно объяснить баллистическим перемешиванием.

Энергия, которую осаждаемые атомы вольфрама могут передать поверхностным атомам слоя кремния, включает в себя удельную теплоту конденсации ( $\mathrm{E}_{\mathrm{C}} \sim 8,5$ эВ/атом), среднюю кинетическую энергию прибывающих атомов $\left(\mathrm{E}_{\mathrm{K}} \sim 32,5\right.$ эB/атом) и теплоту, которая выделяется в результате образования $\mathrm{WSi}_{2}$ $\left(\Delta \mathrm{H}_{298} \sim 0,85\right.$ эВ/атом). Кроме того, небольшое количество энергии приходит на подложку с отраженными от вольфрамовой мишени атомами аргона $\left(\mathrm{E}_{\mathrm{Ar}} \sim\right.$ эВ/атом). В результате мы получаем общую энергию $\mathrm{E}(\mathrm{W})=\mathrm{E}_{\mathrm{C}}+\mathrm{E}_{\mathrm{K}}+\Delta \mathrm{H}_{298}+\mathrm{E}_{\mathrm{Ar}} \approx 46$ эB/атом, которая может выделиться на нижней границе (W-на-Si). Этой энергии достаточно, чтобы расплавить слой кремния, на который осаждаются атомы вольфрама, однако, учитывая, что она выделяется не мгновенно, а в течение продолжительного времени (секунды), плотность энергии может значительно понизиться за счет отвода тепла в подложку.

Зная скорость осаждения и время напыления слоев вольфрама, которые обеспечивают формирование нижней силицидной прослойки, мы можем оценить коэффициент диффузии атомов вольфрама в слой кремния [40]: $D_{\mathrm{W}}=\left(0,6 \times 10^{-7} \mathrm{~cm}\right)^{2} / 4,767 \mathrm{c} \approx 7,6 \times 10^{-16} \mathrm{~cm}^{2} / \mathrm{c}$. Здесь мы учли, что $\sim 1,2$ нм в нижней силицидной прослойке может образовываться по баллистическому механизму, а 1,8-1,2 0,6 нм - по диффузионному. Уравнение Аррениуса для коэффициента диффузии в пленочной системе вольфрам-кремний, как показано в [41], имеет вид $\mathrm{D}=5,59 \times 10^{-5} \exp (-1,35 \ni \mathrm{B} / \mathrm{kT})$. Подставляя полученный коэффициент диффузии $\mathrm{D}_{\mathrm{W}}$ в это уравнение, мы получаем, что эффективная температура в нижней силицидной прослойке составляет $626 \mathrm{~K}$ (kT 0,05 эВ). Такая энергия почти на 3 порядка меньше энергии, которая поступает на поверхность слоя кремния с атомами вольфрама, т.е. в разогреве поверхности слоев кремния принимает участие незначительная часть энергии, прибывающая на поверхность с атомами вольфрама. Эффективная температура поверхности осаждаемого слоя, как видно из наших оценок, заметно выше температуры подложки $(<350 \mathrm{~K})$. Повышение температуры на поверхности осаждаемых слоев также наблюдалась и другими авторами [42], что мы связываем с низкой теплопроводностью пленок, как двумерного объекта как такового [43]. 
Из оценок, сделанных выше, можно прийти к заключению, что образование силицидной прослойки на нижней межфазной границе (W-на-Si) проходит преимущественно по баллистическому механизму, т.е. большая часть силицидного слоя ( $\mathrm{t} \leq 1,2$ нм) образуется за счет механического внедрения атомов вольфрама в слои кремния, а меньшая часть ( $\mathrm{t} \geq 0,6$ нм) - по диффузионному механизму, т.е. за счет разогрева поверхности и последующей диффузии.

Таблица 2.

Потенциал на магнетроне $(\mathrm{U})$; энергия распыленных атомов $\left(\mathrm{E}_{\mathrm{K}}\right)$; материал слоя на подложке; глубина проникновения распыленных атомов в материал слоя на подложке при нормальном падении $\left[\mathrm{X}\left(0^{\circ}\right)\right]$ и при $45^{\circ}$

$\left[\mathrm{X}\left(45^{\circ}\right)\right]$; общая энергия распыленных атомов $(\mathrm{E})$; коэффициент диффузии в силицидных прослойках (D); ожидаемая температура в силицидных прослойках (T) .

\begin{tabular}{|c|c|c|c|c|c|c|c|c|}
\hline Атом & $\mathrm{U}_{\mathrm{W}(\mathrm{Si})}, \mathrm{B}$ & $\mathrm{E}_{\mathrm{K}}$, эB & $\begin{array}{c}\text { Слой на } \\
\text { подложке }\end{array}$ & $\mathrm{X}\left(0^{\circ}\right), \mathrm{HM}$ & $\mathrm{X}\left(45^{\circ}\right), \mathrm{HM}$ & $\mathrm{E}(\mathrm{W}, \mathrm{Si})$, эВ & $\mathrm{D} \times 10^{16}, \mathrm{~cm}^{2} / \mathrm{c}$ & $\mathrm{T}, \mathrm{K}$ \\
\hline \multirow{3}{*}{$\mathrm{W}$} & \multirow{3}{*}{550} & \multirow{3}{*}{32,5} & $\mathrm{Si}$ & 1,7 & 1,2 & \multirow{3}{*}{$\sim 46$} & - & - \\
\hline & & & $\mathrm{WSi}_{2}$ & 1 & 0,7 & & $\sim 7,6$ & $\sim 626$ \\
\hline & & & $\mathrm{W}_{5} \mathrm{Si}_{3}$ & 0,6 & 0,4 & & - & - \\
\hline \multirow{3}{*}{$\mathrm{Si}$} & \multirow{3}{*}{650} & \multirow{3}{*}{11,2} & $\mathrm{WSi}_{2}$ & 0,4 & 0,3 & \multirow{3}{*}{$\sim 15,5$} & $\sim 64,3$ & $\sim 685$ \\
\hline & & & $\mathrm{W}_{5} \mathrm{Si}_{3}$ & 0,3 & 0,3 & & - & - \\
\hline & & & $\mathrm{W}$ & 0,3 & 0,3 & & - & - \\
\hline
\end{tabular}

Аналогично для атомов кремния при потенциале на кремниевой мишени $\mathrm{U}_{\mathrm{Si}} \sim 650 \mathrm{~B}$ средняя кинетическая энергия распыленных атомов составляет $\mathrm{E}_{\mathrm{K}} \sim 11,2$ эВ/атом. Несмотря на то, что средняя энергия атомов кремния примерно в 3 раза ниже по сравнению с распыленными атомами вольфрама, средняя энергия, приходящаяся на одну молекулу дисилицида, в случае распыления кремния меньше только на 30\%, поскольку на одну молекулу приходится 2 атома кремния. Проникновение атомов кремния в слои вольфрама и всех его силицидов, согласно расчетам TRIM, не превышает 0,3 нм (таблица 2). При общей толщине верхней силицидной прослойки 0,9 нм, очевидно, что баллистическое перемешивание может обеспечить формирование только трети этой прослойки. Аналогичные процедуры с удельной теплотой конденсации ( $\mathrm{E}_{\mathrm{C}} \sim 3,97$ эВ/атом), средней кинетической энергией атомов и теплотой образования силицида на верхней границе $(\mathrm{Si}-\mathrm{Ha}-\mathrm{W})$ дают общую энергию для атомов кремния $\mathrm{E}(\mathrm{Si})=\mathrm{E}_{\mathrm{C}}+\mathrm{E}_{\mathrm{K}}+\Delta \mathrm{H}_{298}=4+11,2+0,85 \times 0,4 \approx 15,5$ эВ/атом, которой достаточно, чтобы расплавить верхний силицидный слой. Таким же образом по скорости осаждения кремния и толщине “диффузионной” составляющей силицидного слоя мы определили коэффициент диффузии атомов кремния в слои вольфрама: $\mathrm{D}_{\mathrm{Si}}=\left(0,6 \times 10^{-7} \mathrm{~cm}\right)^{2} / 0,56 \mathrm{c} \approx 6,43 \times 10^{-15} \mathrm{~cm}^{2} / \mathrm{c}$. Эта величина примерно в 8 раз выше коэффициента диффузии $\mathrm{D}_{\mathrm{W}}$ для нижней силицидной прослойки. Несмотря на то, что в системе W-Si кремний является преобладающим диффузантом [43], мы полагаем, что здесь в таком различии нет каких-либо физических особенностей, и большая величина для $\mathrm{D}_{\mathrm{Si}}$ связана с более высокой скоростью осаждения слоев кремния (почти в 3 раза) по сравнению со скоростью осаждения вольфрама, т.е. в данном случае плотность выделяемой энергии на поверхности слоев вольфрама выше. Опираясь на вышеприведенное уравнение Аррениуса, мы получили эффективную температуру поверхности верхней силицидной прослойки $685 \mathrm{~K}$, т.е. всего на $\sim 60^{\circ}$ выше, чем на нижней силицидной границе. Таким образом, из расчетов, сделанных в данном параграфе, можно прийти к заключению, что верхняя силицидная прослойка ( $\mathrm{Si}-$ на-W) формируется преимущественно по диффузионному механизму, т.е. большая часть силицидного слоя ( $\mathrm{t} \leq 0,6$ нм) образуется диффузионным путем, и меньшая часть $(\mathrm{t} \geq 0,3$ нм) - путем механического внедрения атомов кремния в слои вольфрама.

Из данных, приведенных в данном подразделе, следует, что для многослойной системы W-Si возможно 2 подхода к снижению взаимодействия на межфазных границах $\mathrm{Si}$ и $\mathrm{W}: 1)$ уменьшение энергии распыленных атомов, например путем понижения напряжения горения магнетронов либо повышения давления рабочего газа с целью термализации распыленных атомов [44]; 2) снижение скорости осаждения. Снижение энергии осаждаемых атомов может вызвать развитие шероховатости [45]. Кроме того, оба подхода предполагают снижение скоростей осаждения, что может привести к повышенному содержанию нежелательных примесей $(\mathrm{O}$, $\mathrm{C}, \mathrm{N}$ ), отрицательный результат чего может проявиться, например, в повышении поглощения слоев либо в неравномерном взаимодействии слоев, что, в конечном счете, повлияет на шероховатость. Все это неизменно скажется на эффективности МРЗ. Поэтому оба подхода требуют оптимизации, т.е. проведения дополнительных исследований.

\section{ВЫВОДЫ}

Методами рентгеновской дифрактометрии исследована структура и фазовый состав многослойных рентгеновских зеркал (MP3) W/Si, которые используются в качестве рентгено-оптических элементов в мягкой рентгеновской области ( $\lambda=0,7-3,1$ нм). Проведенные исследования позволяют сделать следующие выводы:

1. Слои вольфрама толщиной $2,7<\mathrm{t}_{\mathrm{W}}<10$ нм имеют поликристаллическую (ОЦК) структуру. В кристаллических слоях действуют растягивающие напряжения, которые не превышают 1,1 ГПа. При толщинах 
вольфрама $\mathrm{t}_{\mathrm{W}}<1,9$ нм МР3 становятся полностью аморфными. Во всех слоях вольфрама содержится, по меньшей мере, 3 ат.\% кремния.

2. Аморфные слои вольфрама имеют структуру, близкую к $\beta$-W. В прослойках на обеих межфазных границах присутствует аморфный дисилицид вольфрама $\left(\mathrm{WSi}_{2}\right)$. В зависимости от скорости осаждения вольфрама структура прослоек меняется от тетрагональной (t-WSi $\mathrm{W}_{2} ; 0,6 \mathrm{HM} / \mathrm{c}$ ) до гексагональной (h-WSi ${ }_{2}$; $\sim 0,15 \mathrm{HM} / \mathrm{c})$.

3. Для зеркал $\mathrm{c} \mathrm{t}_{\mathrm{W}}>1,3$ нм уточнена модель строения аморфных MP3 W/Si, осажденных с маленькой скоростью напыления вольфрама $(\sim 0,15$ нм/с), согласно которой аморфный вольфрам имеет расположение атомов, близкое к $\beta$-W. На верхней и нижней (по отношению к слоям вольфрама) межфазных границах присутствуют аморфные силицидные прослойки, содержащие $\mathrm{WSi}_{2}$, близкий по расположению атомов к гексагональному $\mathrm{WSi}_{2}$. Нижняя прослойка состоит в основном из дисилицида. Верхняя прослойка состоит частично из дисилицида вольфрама, а частично из аморфного вольфрама.

4. Предложены механизмы формирования силицидных прослоек, согласно которым нижняя силицидная прослойка (граница $\mathrm{W}$-на-Si) формируется преимущественно вследствие баллистического перемешивания, а верхняя силицидная прослойка (Si-на-W) образуется преимущественно по диффузионному механизму.

5. Сделаны оценки коэффициентов диффузии в силицидных прослойках, которые позволили установить, что эффективная температура поверхности осаждаемых слоев может быть, по меньшей мере, на $250^{\circ}$ выше температуры подложки.

\section{БЛАГОДАРНОСТИ}

Автор выражает благодарность ISKCON за помощь в понимании роли и значимости данной работы.

\section{СПИСОК ЛИТЕРАТУРЫ}

1. Uspenskii Yu., Burenkov D., Hatano T., Yamamoto M. Optimal design of multilayer mirrors for Water-Window microscope optics // Opt. Rev. - 2007. - Vol. 14. - P.64-73.

2. Artyukov I., Bugayev Ye., Devizenko O., Gullikson E., Kondratenko V., Vinogradov A. X-ray Schwarzschild objective for the carbon window $(\lambda \sim 4.5 \mathrm{~nm}) / /$ Opt. Let. - 2009. - Vol. 34. - P.2930-2932.

3. Mojarad N., Gobrecht J., Ekinci Y. Beyond EUV lithography: a comparative study of efficient photoresists' performance // Scientific Reports. - 2015. - Vol. 5. - P. 9235.

4. Spiller E. Recent advances in X-ray optics // Proc. SPIE: Laser-Generated, Synchrotron, and Other Laboratory X-Ray and EUV Sources, Optics, and Applications II / Ed. by G.A. Kyrala et al. - San Diego, California, 2005. - Vol. 5918. - P. 591806.

5. Singh K.P. Grazing incidence optics for X-ray astronomy // Journal of Optics. - 2011. - Vol. 40. - P.88-95.

6. Heilmann R.K., Ahn M., Gullikson E.M., Schattenburg M.L. Blazed high-efficiency x-ray diffraction via transmission through arrays of nanometer-scale mirrors // Optics Express. - 2008. - Vol. 16. - P.8658-8669.

7. Wang Y., Yun W., Jacobsen C. Achromatic Fresnel optics for wideband extreme-ultraviolet and X-ray imaging // Nature. 2003. - Vol. 424. - P.50-53.

8. Braun S., Gawlitza P., Menzel M., Leson A., Mertin M., Schäfers F. Reflectance and Resolution of Multilayer Monochromators for Photon Energies from $400-6000 \mathrm{eV} / /$ Synchrotron Radiation Instrumentation: 9th International Conference / Ed. by J.-Y. Choi et al. - Daegu, Korea, 2006. - P.493-496.

9. Kuki M., Uemura T., Yamaguchi M., Harada T., Watanabe T., Muramatsu Y., Kinoshita H. Development of high-reflective W/Si diffraction grating for the analysis of fluorine materials. // Journal of Photopolymer Science and Technology. - 2015. Vol. 28. - P.531-536.

10. Windt D.L., Christensen F.E., Craig W.W., Hailey C., Harrison F.A., Jimenez-Garate M., Kalyanaraman R., Mao P.H. Growth, structure, and performance of depth-graded W/Si multilayers for hard x-ray optics // Journal of Applied Physics. - 2000. - Vol. 88. - P.460-470.

11. Sell B., Sanger A., Schulze-Icking G., Pomplun K., Krautschneider W. Chemical vapor deposition of tungsten silicide (WSi ) for high aspect ratio applications // Thin Solid Films. - 2003. - Vol. 443. - P.97-107.

12. Pauleau Y., Dassapa F.C., Lami Ph., Oberlin J.C., Romagna F. Silicide formation in metal/Si structures and diffusion barrier properties of CVD tungsten films // Journal of Material Research. - 1989. - Vol. 4. - P.156-162.

13. Wang M.T., Lin Y.C., Lee J.Y., Wang C.C., Chen M.C. Thin-Film Properties and Barrier Effectiveness of Chemically Vapor Deposited Amorphous WSi ${ }_{x}$ Film // J. Electrochem. Soc. - 1998. -Vol. 145. - P.4206-4211.

14. Backhouse C.J., Este G., Sit J.C., Dew S.K., Brett M.J. WSi $x_{x}$ thin films for resistors // Thin Solid Films. - 1997. - Vol. 311. P.299-303.

15. Fujimura N., Tachibana S., Ito T., Hosokawa N. Structural control of nonequilibrium $\mathrm{WSi}_{2.6}$ thin films by external stress // Journal of Applied Physics. - 1993. - Vol. 73. - P.733-739.

16. Tung B.T., Dao D.V., Toriyama T., Sugiyama S. Measurement of mechanical and thermal properties of co-sputtered WSi thin film for MEMS applications // Microsystem Technologies. - 2010. - Vol. 16. - P.1881-1886.

17. Divochiy A., Marsili F., Bitauld D., Gaggero A., Leoni R., Mattioli F., Korneev A., Seleznev V., Kaurova N., Minaeva O., Gol'tsman G., Lagoudakis K.G., Benkhaoul M., Levy F., Fiore A. Superconducting nanowire photon-number-resolving detector at telecommunication wavelengths // Nature Photonics. - 2008. - Vol. 2. - P.302-306.

18. Marsili F., Verma V.B., Stern J.A., Harrington S., Lita A.E., Gerrits T., Vayshenker I., Baek B., Shaw M.D., Mirin R.P., Nam S.W. Detecting single infrared photons with 93\% system efficiency // Nature Photonics. - 2013. - Vol. 7. - P.210-214.

19. Lukovic J., Zagorac D., Schön J.C., Zagorac J., Jordanov D., Volkov-Husovic T., Matovic B. // Tungsten Disilicide (WSi ${ }_{2}$ ): Synthesis, Characterization, and Prediction of New Crystal Structures. - 2017. - Vol. 643. - P.2088-2094. 
20. Stoetzel J., Schneider T., Mueller M.M., Kleebe H.-J., Wiggers H., Schierning G., Schmechel R. Microstructure and thermoelectric properties of $\mathrm{Si}_{-} \mathrm{WSi}_{2}$ nanocomposites // Acta Materialia. - 2017. - Vol. 125. - P.321-326.

21. Koch F., Bolt H. Self passivating W-based alloys as plasma facing material for nuclear fusion // Phys. Scr. - 2007. - Vol. T128. - P.100-105.

22. Pershin Yu.P., Devizenko A.Yu., Mamon V.V., Chumak V.S., Kondratenko V.V. Struktura, fazovyj sostav i model' rosta amorfnyh mnogoslojnyh rentgenovskih zerkal W-Si, izgotovlennyh metodom magnetronnogo raspylenija [Structure, phase composition and growth model of amorphous multilayer X-ray mirrors W-Si deposited by magnetron sputtering // Zhurnal fiziki i inzhenerii poverhnosti [Journal of Physics and Surface Engineering]. - 2016. - Vol. 1. - No. 1. - P.27-41. (in Russian)

23. Metallichekie stekla [Glassy Metals II] - Atomnaja struktura i dinamika, elektronnaja struktura, magnitnye svoistva [Atomic Structure and Dynamics, Electron Structure, Magnetic Properties] (Transl. from Engl.) / Ed. Beck H. et al. - Moscow: Mir, 1986. - 456 P. (in Russian).

24. International Centre for Diffraction Data (JCPDS), PCPDFWIN \#040806, 2000.

25. Bajt S., Stearns D.G., Kearney P.A. Investigation of the amorphous-to-crystalline transition in Mo/Si multilayers // Journal of Applied Physics. - 2001. - Vol. 90. - P.1017-1025.

26. Andreev S.S., Gaponov S.V., Gusev S.A., Haidl M.N., Kluenkov E.B., Prokhorov K.A., Polushkin N.I., Sadova E.N., Salashchenko N.N., Suslov L.A., Zuev S.Yu. The microstructure and X-ray reflectivity of Mo/Si multilayers // Thin Solid Films. - 2002. - Vol. 415. - P.123-132.

27. Zubarev E.N., Kondratenko V.V., Pershyn Yu.P., Sevryukova V.A. Growth and crystallization of molybdenum layers on amorphous silicon // Thin Solid Films. - 2011. - Vol. 520. - P.314-319.

28. Krüger M., Franz S., Saage H., Heilmaier M., Schneibel J.H., Jehanno P., Boning M., Kestler H. Mechanically alloyed Mo-SiB alloys with a continuous a-Mo matrix and improved mechanical properties // Intermetallics. - 2008. - Vol. 16. - P.933-941.

29. Diagrammy sostojanija dvoinyh metallicheskih sistem [Constitution diagram of binary metallic systems]. - Handbook, Vol. 3 / Ed. N.P. Ljakishev. - Moscow: Machine-building, 2000. - 448 P. (in Russian)

30. Gautier J., Delmotte F., Bridou F., Ravet M.F., Varniere F., Roulliay M., Jerome A., Vickridge I. Characterization and optimization of magnetron sputtered Sc/Si multilayers for extreme ultraviolet optics // Appl. Phys. A. - 2007. - Vol. 88. P.719-725.

31. Pinegyn V.I., Zubarev E.N., Kondratenko V.V., Sevryukova V.A., Yulin S.A., Feigl T., Kaiser N. Structure and stressed state of molybdenum layers in Mo/Si multilayers // Thin Solid Films. - 2008. - Vol. 516. - P.2973-2980.

32. International Centre for Diffraction Data (JCPDS), PCPDFWIN \#441055; 2000.

33. Mal'tsev V.M. Metallografija promyshlennyh tsvetnyh metallov i splavov [Metallography of industrial nonferrous metals and alloys]. - Moscow: Metallurgy, 1970. - 364 P. (in Russian)

34. Morcom W.R., Worrell W.L., Sell H.G., Kaplan H.I. The Preparation and characterization of $\beta$-Tungsten, a metastable tungsten phase // Metallurgical transactions. - 1974. - Vol. 160. - P.155-161.

35. Doland C.M. Molybdenum silicide formation on single crystal, polycrystalline and amorphous silicon: growth, structure and electrical properties // Dissertation for the PhD degree. - Houston: University of Houston-University Park, 1988. - 332 p.

36. Jarrige I., Capron N., Jonnard P. Electronic structure of Ni and Mo silicides investigated by X-ray emission spectroscopy and density functional theory // Physical Review. - 2009. - Vol. 79. - 035117.

37. Fujiwara H., Ueda Y., Awasthi A., Krishnamurthy N., Garg S.P. Determination of the standard free energies of formation for tungsten silicides by EMF measurements using lithium silicate liquid electrolyte // Journal of Alloys and Compounds. - 2005. Vol. 391. - P.307-312

38. Pretorius R. Prediction of silicide formation and stability using heats of formation // Thin Solid Films. - 1996. - Vol. 290-291. P.477-484.

39. http://www.srim.org/SRIM/SRIMLEGL.htm

40. Largeron C., Quesnel E., Thibault J. Interface growth mechanism in ion beam sputtering-deposited Mo/Si multilayers // Philosophical Magazine. - 2006. - Vol. 86. - P.2865-2879.

41. De Luca A., Portavoce A., Texier M., Grosjean C., Burle N., Oison V., Pichaud B. Tungsten diffusion in silicon // J. Appl. Phys. - 2014. - Vol. 115. - P.013501.

42. Shaginyan L.R., Han J.G., Shaginyan V.R., Musil J. Evolution of film temperature during magnetron sputtering // J. Vac. Sci. Technol. A. - 2006. - Vol. 24. - P.1083-1090.

43. Murarka S.P. Silicides for VLSI application. - Bell Telephone Lab. Inc., 1983. - 176 p.

44. Pershyn Y.P., Gullikson E.M., Kondratenko V.V., Mamon V.V., Reutskaya S.A., Voronov D.L., Zubarev E.N., Artyukov I.A., Vinogradov A.V. Effect of working gas pressure on interlayer mixing in magnetron-deposited Mo/Si multilayers // Optical Engineering. - 2013. - Vol.52. - P.095104.

45. Windt D.L., Hull R., Waskiewicz W.K. Interface imperfections in metal/Si multihyers // J. Appl. Phys. - 1992. - Vol. 71. P.2675-2678. 